\title{
O Bandido à Luz das Molduras
}

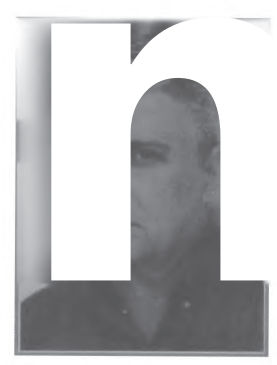




\title{
Resumo
}

Este trabalho propõe uma leitura de $\mathrm{O}$ bandido da luz vermelha, de Rogério Sganzerla, a partir de um instrumental teórico criado pelo Groupe p. para a análise de quadros. Embora possa parecer extravagante, tal aproximação tem caráter investigativo-experimental e visa, em termos mais imediatos, dar conta das inusitadas articulações retóricas que se podem vislumbrar neste texto fílmico à luz da noção de moldura.

\section{Palavras-chave}

moldura, retórica, cinema.

\begin{abstract}
This work proposes a reading of Red light banditi, a film by Rogério Sganzerla, departing from a theoretical background created by Groupe $p$ for the analysis of paintings. Although it seems to be uncommon, this approach has the nature of an experimental investigation, and aims, in a first instance, at the study of the unusual rhetorical articulations that can be apprehended in the filmic text within the notion of the frame structure.
\end{abstract}

\section{Key words}

frame, rhetoric, cinema. 
bandido da luz vermelha, 1 filme de Rogério Sganzerla, lembra uma colagem na qual se podem distinguir, com relativa facilidade, vários ícones; mas se torna difícil estabelecer, pelo menos num primeiro momento, relação entre eles. Como nas obras pop dos anos sessenta, encontramos em $\mathrm{O}$ bandido os emblemas da sociedade pós-industrial urbana - automóveis, aviões, televisores, cinema, TV -, mas há também, em grande quantidade, objetoskitsch, como uma instigante representação de uma esfinge e enigmáticas figuras e imagens de São Jorge. No áudio, sucedem-se boleros, tangos, sambas-canção, rumbas; e nas locações, entre mansões e arranha-céus paulistanos, emergem, em sucessão de rápidos cortes, a penumbra dos inferninhos, a escuridão dos becos, a

1. Este texto foi desenvolvido durante o curso "Cinema Brasileiro: Alegoria e Tropicalismo", ministrado pelo professor Ismail Xavier, no primeiro semestre de 1991, na ECA/USP. Mais tarde, depois de sofrer uma ou outra modificação, foi aproveitado para compor parte do corpus de minha tese. O filme foi produzido em 1968 (Urano), com $92 \mathrm{~min}$ de duração, e tem no elenco, entre outros, os atores Paulo Villaça, Helena Ignez, Luiz Linhares e Pagano Sobrinho. Segundo o pesquisador Fernão Ramos, "O bandido é um filme marco que, se quisermos traçar linhas demarcatórias, pode ser considerado como o ponto de partida para o que mais tarde seria o Cinema Marginal [...] A capacidade de deglutiçãoé exatamente o que, a meu ver, distingue 0 bandido do Cinema Novo [...]" (1987, p. 78). 
pobreza da favela. Nas largas avenidas, nas ruas apertadas, o grito lancinante e a pulsação luminosa da sirene da polícia tomam conta da noite, que se fragmenta.

Essa justaposição do moderno com o que parece ou sugere arcaico é uma postura que acaba de ser posta em voga pelos tropicalistas - o filme foi produzido em 1968. Não há, no entanto, como acontece muitas vezes na música popular, nenhum resquício de saudosismo nostálgico, nem muito menos deslumbramento com os ícones modernos. Tudo parece se equivaler e se integrar no que se evidencia como uma metáfora da sociedade brasileira: a Boca do Lixo.

É nesse sentido que o filme de Sganzerla ganha um forte cunho antropofágico e vai encontrar suas raízes no modernismo oswaldiano.

Seria por mero acaso que a primeira imagem "congelada" do filme, que entra logo após um painel eletrônico ter anunciado os créditos principais, tenha sido a da devoradora esfinge? Parece-me que não, mesmo porque será justamente essa a postura do autor do texto fílmico em relação ao material recolhido e ao seu tratamento. Tudo é deglutido com um apetite voraz, do qual não se exclui o próprio pai - a referência ao mito edipiano sinaliza isso -, mesmo que seja por meio de sua herança cultural, representada, no caso, principalmente pela obra de Glauber Rocha, à qual Sganzerla insistentemente retorna, embora nem sempre de maneira explícita.

Do ponto de vista narrativo, o filme evolui aos saltos, que subvertem as noções naturalistas de tempo e espaço, e a própria identidade do protagonista fica comprometida. O resultado são ações fragmentadas e desconexas, que são "alinhavadas" por narradores intra e extradiegéticos. Em vez de esclarecer, no entanto, esses narradores confundem a inteligibilidade da ação, pois se contradizem e divergem uns dos outros. Mais do que isso, parecem narrar não só de pontos de vista diferentes, mas também a partir de temporalidades diferenciadas.

O ponto de vista de Jorge, o personagem narrador, é retrospectivo e

Significação $13 \quad \cdot 146$ 
onisciente em relação à ação: fala a respeito de seu passado, de coisas que já viveu, embora não tenha "certeza de nada" O casal de radialistas narra de um tempo presente, mas suas especulações, suas contradições e enumeração de fatos desconexos comprometem a veridicção do seu relato. O painel eletrônico, ao qual se pode considerar um terceiro narrador, ${ }^{2}$ parece tudo registrar em sua aparente imparcialidade, mas seu fluxo contínuo nada articula e sua emergência no texto enunciado é extemporânea. O conteúdo de seu relato também diverge do apresentado pelos demais narradores, não propriamente nos temas tratados, mas na sua versão, no seu en,foque distanciado e supostamente objetivo.

O grau de insegurança que esses narradores criam para o espectador é tal que, como acontece com o personagem narrador na diegese, ninguém tem certeza de nada. O bandido nasceu na favela?, em Bauru?, no Mato Grosso?, ou no Paraguai? Ele é apenas um, ou são dois? É um bandido comum, assaltante e tarado, ou um terrorista político? $\mathrm{E}$ o que significa um JB, o candidato à Presidência saído da Boca do Lixo?

Considerando-se essas lacunas não há como escapar de uma interpretação alegórica do filme, ou seja, uma leitura que vai buscar no contexto social imediato o seu interpretante, como acontece, aliás, com várias produções cinematográficas dessa época, período em que se colocava na mesma vala comum todos os marginalizados. Assim, se a Boca podia ser o Brasil, o bandido da luz vermelha era o terrorista; JB representava os políticos; o delegado Cabeção, a repressão...

Em 1968, quando o filme foi lançado não era nada difícil, acredito, estabelecer tais homologações. Os bem informados, certamente, chegavam um pouco mais longe: identificavam o que o filme devia a Glauber, a Orson Welles, a Godard, e podiam avaliara cultura cinema-

2. Em alguns momentos, no entanto, como quando apresenta os créditos principais do filme, o painel eletrônico extrapola suas funções de narrador. Mas é mesmo neste momento inicial, ao intercalar informações sobre a diegese com dados da produção do filme, que ele se revela como narrador. A bem dizer, a narrativa começa com a frase "um gênio ou uma besta" que o painel eletrônico veicula antes mesmo dos créditos.

Significação $13 \cdot 147$ 
tográfica do autor. Ou seja, apesar das rupturas e das surpresas, o filme de Sganzerla sempre foi legível. Fez sucesso e ganhou prêmios. ${ }^{3}$ Não obstante, continua a intrigar e suscitar novas leituras. ${ }^{4}$

\section{Dois}

Por me parecer um instrumento adequado para desvendar certos procedimentos da complexa linguagem deste filme, resolvi lançar mão de um arcabouço teórico criado pelo Groupe $\mathrm{p}$ para a análise de quadros. ${ }^{5}$ Os retóricos belgas partem da distinção de Meyer Shapiro de que o quadro é "um fechamento regular que isola o campo da representação da superfície circunstante" e introduzem dois novos conceitos que permitem, como enfatizam, o aprofundamento da questão: o contorno e a moldura.

3. O bandido da luc vermelha conquistou o Prêmio do Festival de Brasília em 1968.

4. Mais de vinte anos depois do lançamento do filme, em 1991, Jean Claude Bernardet lança o livro de ensaios $\mathrm{O}$ vôo dos anjos, e analisa cinco filmes do período que se seguiu ao fim do Cinema Novo - um deles é 0 bandido. Pouco depois (1993), em. Alegorias do subdesenvolvimento, Ismail Xavier também dedica um de seus ensaios a $O$ bandido. Claro que essas retomadas, em função de seus objetivos, ocupam espaços não explorados na época do lançamento do filme e chamam a atenção para a incompreensão da crítica especializada daquela época, como destaca Jean-Claude na introdução de seu livro. No entanto, embora certamente o tempo tenha contribuído para deixar mais evidentes as inovações do filme e o que foi mobilizado pela sua fatura, as condições para a sua legibilidade, acredito, estavam lá, e é a isso que me refiro quando digo que o filme sempre foi legível.

5. Por acaso, na oportunidade em que este trabalho estava sendo idealizado, ainda me debatia com uma cópia xerográfica de "Sémiotique et rhétorique du cadre", texto que o professor Peñuela Cañizal indicara no curso Poética das Mensagens Não-Verbais, proferido na ECA/USP no ano anterior, para servir como um dos instrumentais teóricos para leitura de objetos não-verbais, entre os quais quadrinhos de Quino e telas de Dali e Magritte. Talvez ainda motivado pelo incentivo à experimentação, que foi a tônica daquele curso, comecei a ler 0 bandido a partir do instrumental criado pelos teóricos de Liège para analisar quadros. Para minha surpresa, a leitura se revelou produtiva, o que me levou a prosseguir e registrar o que considero seu esquema básico para que o leitor, se estiver disposto, possa entrar nesse jogo e, quem sabe?, ir às fontes para delas fazer melhor proveito (ver Bibliografia). 
Entendem por contorno o traço não material que divide o espaço em duas regiões, para criar, em termos gestálticos, o fundo e a forma. $O$ contorno distingue-se do simples limite; topologicamente apresenta um interior e um exterior, embora pertença perceptivamente à imagem identificada. É, pois, um percepto que intervém na delimitação de unidades e de conjuntos ¡cónicos e/ou plásticos. Pode ser mais ou menos marcado, segundo a imagem se destaque do fundo em maior ou menor número de planos (cor, textura etc.).

A moldura, por sua vez, designa o artificio que, num espaço dado, determina uma unidade orgânica: um enunciado de ordem ¡cónica ou plástica. Embora se manifeste materialmente (um traçado quadrangular, triangular ou oval; de madeira ou de metal; abstrato ou jcónico), não se define por sua aparência ou substância, e sim por sua função semiótica. A moldura é um signo da família do ícone, e seu significado pode ser glosado:

a) tudo o que está compreendido em seus limites recebe estatuto semiótico (quer dizer, é significativo);

b) constitui um enunciado distinto daqueles que poderiam ser percebidos no espaço exterior a esses limites;

c) é sobre o conjunto de signos contidos nesse espaço que a atenção do espectador deve se focalizar;

d) mesmo um vazio, quando envolvido por urna moldura, recebe um estatuto semiótico;

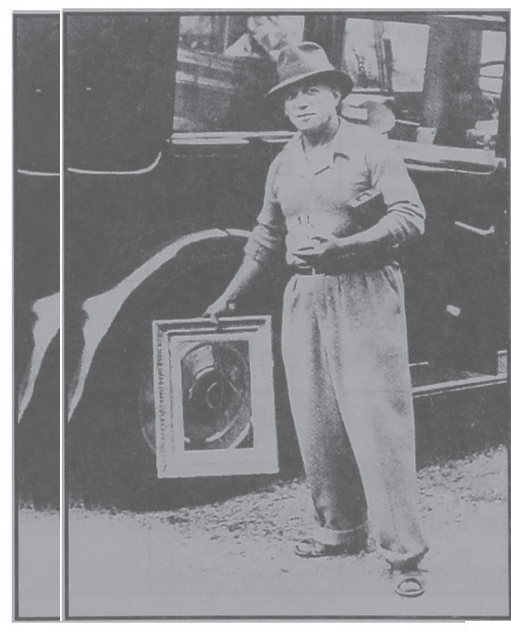

e) um objeto do mundo, como uma escada ou um sapato, é desqualificado pela moldura enquanto objeto do mundo ou de outro discurso para se converter num signo de um enunciado específico. 
A função indiciai da moldura poderá ser orientada nesta ou naquela direção e enriquecida semánticamente por um processo retórico. E, como toda retórica, a do quadro supõe o estabelecimento de uma norma que, no caso, tem o pressuposto lá anunciado: o espaço referido pela moldura é o lugar de um enunciado explicitamente dado. Em relação a esta norma, podem se estabelecer figuras retóricas porsupressão, adjunção, e porsupressão adjunção. E, como se pode pensar em Figuras do contorno, Figuras da moldura/significado, Figuras da moldura/significante e, ainda,Figuras da relação entre moldura e enunciado, os retóricos do GroupejJ. montaram um quadro de relações que apresentamos abaixo, com adaptações:

\begin{tabular}{|c|c|c|c|c|}
\hline \multicolumn{1}{|c|}{12} & $\begin{array}{c}\text { Fig. do } \\
\text { Contorno }\end{array}$ & $\begin{array}{c}\text { Fig. da Moldura/ } \\
\text { Significado }\end{array}$ & $\begin{array}{c}\text { Fig da } \\
\text { Moldura/ } \\
\text { Significante }\end{array}$ & $\begin{array}{c}\text { Fig. da relação } \\
\text { Moldura/ } \\
\text { Enunciado }\end{array}$ \\
\hline Norma & $\begin{array}{c}\text { Redundância } \\
\text { de demarcações }\end{array}$ & $\begin{array}{c}\text { Concomitância } \\
\text { entre } \\
\text { espaço da moldura/ } \\
\text { espaço do enunciado }\end{array}$ & $\begin{array}{c}\text { Oculta mento da } \\
\text { Moldura }\end{array}$ & $\begin{array}{c}\text { Disjunção } \\
\text { Conjunção }\end{array}$ \\
\hline Supressão & $\begin{array}{c}\text { Expansão } \\
\text { Expansão multi- } \\
\text { estável }\end{array}$ & $\begin{array}{c}\text { Transbordamento } \\
\text { Adjunção }\end{array}$ & Destruição & $\begin{array}{c}\text { Moldura Rimada } \\
\text { Mold. Representada } \\
\text { Moldura Icônica }\end{array}$ \\
\hline Supressão/ & Adjunção & Eelimitação & Hipérbole & - \\
\hline
\end{tabular}

1. Figuras do contorno - Tendo como base a norma dada pela redundância das demarcações do contorno, há duas possibilidades para a criação de figuras, ambas por supressão, com o conseqüente

Significação $13 \cdot 150$ 
comprometimento do nível de redundância do contorno, resultando na expansão do enunciado no espaço (Expansão) ou expansão na interseccão entre enunciados (Expansão multiestóvel).

2. Figuras da moldura/significado - O significado da moldura, convém reiterar, é sua função indiciai. Ou seja, designa um espaço à atenção e, portanto, cria uma distinção entre interiore exterior. A norma, neste caso, é a concomitância entre o espaço emoldurado e o espaço do enunciado. A partir desta norma, criam-se três tipos de figuras: 1) por uma operação de supressão obtém-se o Transbordamento, no qual o enunciado ultrapassa os limites da tela, com apropriação do espaço exterior; 2) por uma operação de adjunção chega-se à Delimitação e ao Encolhimento; no primeiro caso (Delimitação), os limites do enunciado são produzidos pela moldura; no Encolhimento (exato contrário do Transbordamento) ocorre o inverso, o espaço emoldurado não é ocupado inteiramente pelo enunciado; 3) por supressão-adjunção constrói-se a Compartimentagem, figura em que o enunciado básico do quadro fica subdividido por molduras interiores, permitindo várias leituras, visões ou pontos de vista.

3. Figuras da moldura/significante - Há figuras que afetam não a função indiciai da moldura (seu significado) mas sim a moldura enquanto objeto significante. A norma, neste caso, é de natureza convencional e histórica. Por exemplo: material - madeira ; forma - retangular ou oval. A norma histórica, no entanto, tende ao Ocultamento da moldura; isto é, ela passa a não ser percebida como tal. Por supressão, obtém-se a Destruição, uma figura pouco notada como desvio da norma em nossos dias. As figuras por adjunção, no caso, são mais freqüentes. No limite, a moldura pode sufocar o enunciado emoldurado a ponto de o fazer desaparecer. O efeito obtido é o da Hipérbole, semelhante ao efeito hiperbólico encontrado nas chamadas molduras Representada e Icônica ostensiva. As operações por supressão-adjunção (ou substituições) são, no caso, complexas e requerem (mais uma vez) o concurso da oposição 
¡Cônico/plástico. ASubstituição e a Deformação transgridem o efeito plástico da moldura - afetam a forma ou a textura, substituindo-as por novas formas e texturas. A outra alternativa consiste em fazer da moldura um signo icônico que vale por um enunciado, colocando-se, assim, sua função indiciai em questão.

4. Figuras da relação moldura/enunciado - A moldura tem um estatuto paradoxal: pertence e não pertence ao espaço indicado, ao enunciado. Mas, evidentemente, não pode se integrar totalmente nele, sob pena de desaparecer enquanto moldura. Considerando apenas a distinção entre moldura e enunciado, percebe-se que sua relação normal é, ao mesmo tempo, conjuntiva edisjuntiva. Conjuntiva porque de acordo com a norma a moldura deve ser pertinente ao enunciado; disjuntiva, para não se confundir com ele. As figuras possíveis serão sempre obtidas por uma operação de supressão. Baixando-se o nível de disjunção entre a moldura e o enunciado, obtém-se a chamada Moldura Rimada ou a Moldura Representada. Na Rimada, a moldura recebe características do enunciado: cor, motivos, textura; na moldura Representada, é o enunciado que recebe características da moldura.

\section{Três}

A moldura, como vimos, é indiciai, indica um interior e um exterior, delimitando o espaço enunciado. Pois bem. O bandido da luz vermelha praticamente começa com uma imagem congelada de uma esfinge (já nos referimos a ela) e termina, pode-se dizer, com a imagem de São Jorge em chamas. Estas duas imagens delimitam um espaço; bastante amplo, é verdade, e repleto de fissuras, mas no qual podemos vislumbrar um enunciado.

Significação 13 

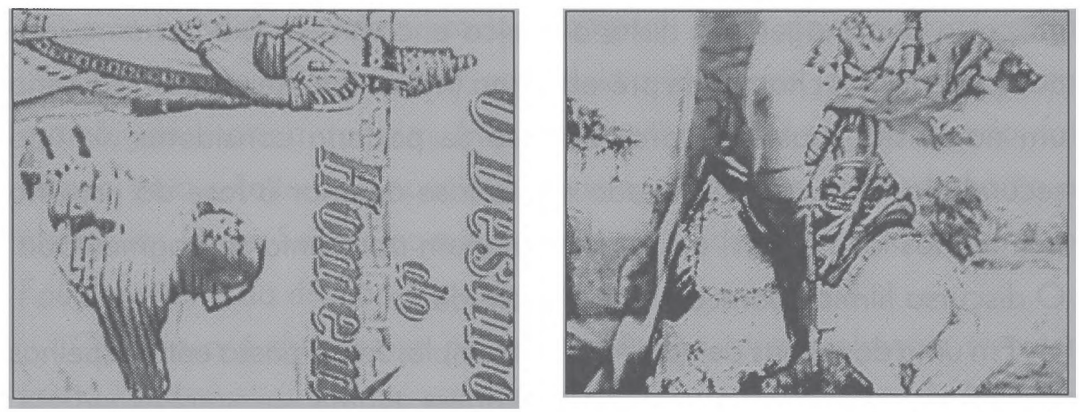

A função desta moldura, no entanto, vai além da simples delimitação deste espaço, ela está investida - é o que procuraremos mostrar - de um conteúdo figurado. Trata-se de uma figura que os retóricos do Groupep classificam como Moldura Representada, que atua na relação entre a moldura e o enunciado (ver quadro). Ela, ao mesmo tempo, diminui o nível de disjunção entre o enunciado e a moldura e confere àquele seus atributos. No filme de Sganzerla, o enunciado que ela delimita define o programa narrativo de Jorge, tanto do ponto de vista de seu ser quanto de seu fazer.

Quando a imagem da esfinge surge na tela, no áudio coloca-se pela primeira vez a questão que será várias vezes reiterada ao longo do filme, direta ou indiretamente: "quem sou eu?" Enigmaticamente, a imagem da esfinge é apresentada após sofrer um giro de noventa graus para a direita. A figura humana, que veste trajes típicos da antiguidade, fica agigantada dada a perspectiva do desenho, e pode-se ler, na vertical, a inscrição "O Destino do Homem". Ao que tudo indica, o autor fotografou uma capa de revista em quadrinhos barata. Não obstante à improvisação grosseira, que deixa transparecer certa ironia, certa esculhambação na própria fatura do filme, a remissão a Édipo fica evidente, e essa vertente norteará todo percurso narrativo do personagem que procura pelo seu ser, pela sua identidade. E, como sugere este Édipo da esfinge, que ainda não sabe ou tem consciência de seus crimes neste ponto da narrativa 
mítica, o personagem da história fílmica encontra-se fixado numa fase que poderíamos chamar de pré-edipiana (no sentido freudiano). Ele seria um narcisista, mas um narcisista que se poderia considerar do tipo secundário, ${ }^{6}$ que teria se fixado numa fase anterior à fase do espelho (em termos lacanianos) e sua auto-imagem apresenta-se fragmentada. O discurso fílmico parece enfatizar esse dado.

Em uma das cenas de assalto, por exemplo, Jorge passa entre espelhos e sua imagem se desdobra em várias figuras. Numa outra oportunidade, quando faz a barba, praticamente divide o espelho em dois com o lenço molhado e, não contente, o lambuza com o creme de barbear, de modo que de seu corpo apenas o rosto seja reproduzido; mas há um espelho grande às suas costas e outro menor na sua lateral, à esquerda, que continuam, malgré lui, a multiplicar sua imagem. Como se não se reconhecesse depois de barbeado, ele usa o creme para embaçar completamente o espelho à sua frente e, em seguida, num gesto ao qual se pode atribuir uma conotação erótica, mas também de dispersão, no sentido que the deu Melanie Klein, segundo Lacan (1986), espalha o creme com o aspersor por todo o banheiro.

Esse processo de busca da identidade que empreende Jorge só termina quando ele se identifica, já no final do filme, com um retrato falado divulgado por um jornal, e toma a decisão de suicídio.

A outra imagem da moldura do filme, a de São Jorge, que antes de aparecer no final da narrativa foi reiterada várias vezes, como figura impressas e como imagem de gesso, revela o outro lado do personagem, o lado bandido de Jorge. Que não por acaso tem esse nome. No roteiro do filme, que não faz referência ao uso das figuras que identificamos como componentes da moldura, o nome de Jorge era. atribuído ao jornalista chefe de reportagem. O que teria feito Sganzerla mudar de idéia? Seu faro de artista ou uma atitude consciente? Pouco importa.

6. Consultar o texto "Os dois narcisismos", in: Seminário - 1 (Lacan, 1986).

Significação $13 \quad \cdot 154$ 
Jorge, o bandido desclassificado, marginal, pária da sociedade, seria um santo guerreiro? A moldura, parte dela pelo menos, já que é composta e ambígua, insinua que sim. Mas seu destino não é ser glorificado, foi selado pelo sujeito da enunciação que queima a imagem do santo e eletrocuta Jorge. Sugere com isso, além da evidente citação à Pierrot le Fou, ${ }^{7}$ a vitória do dragão, cuja arma mortífera é o fogo?

O curioso é que quase na mesma época, provavelmente sem ter conhecimento e nem muito menos ter feito leitura semelhante do filme de Sganzerla, Glauber Rocha usava a mesma imagem de São Jorge para emoldurar o seu Dragão da maldade contra o santo guerreiro, filme lançado em 1969. Mas se isso que acabamos de apontar pode ser visto como um possível acaso, muitas outras referências a Glauber em $\mathrm{O}$ bandido certamente não o são. ${ }^{8}$

O enunciado que "amarra" o duplo programa narrativo de Jorge, porém, não ocupa todo o espaço disponível da película. Uma outra narrativa, embora atípica, fundada antes no mostrar indiciai do que na ação direta, se insinua - inicialmente ocupando apenas a banda sonora - nos temas musicais, na voz dos locutores da rádio Continental de Itapecirica e na do próprio Jorge que a ela se refere com certa freqüência.

É preciso não confundir essa, digamos, segunda narrativa com as histórias paralelas ou interpoladas, como a campanha de JB à Presidência, o caso de Mr. Schmidt, a conferência (brevíssima) que alude aos terroristas mineiros, a invasão dos discos voadores, entre outras, emboras estas

7. Como bem lembram tanto Ismail Xavier quanto Jean-Claude Bernardet, o personagem de Godard, Ferdinand, suicida-se amarrando em seu corpo bananas de dinamite e se faz explodir, ato similar ao tresloucado gesto de Jorge ao se amarrar em fios elétricos para se eletrocutar, embora este ato também faça remissão à morte na cadeira elétrica de que foi vítima o "bandido da luz vermelha" norte-americano, Caryl Chesmann, fato presente no imaginário de Jorge, que projeta como seu possível destino a morte na cadeira elétrica.

8. Ismail Xavier (1993, p. 76) chama a atenção que já Corisco, em Deus e o Diabo na terra do sol, ao expressar a consciência de seu próprio fim, expõe sua teoria sobre o renovado retorno de São Jorge, e assinala que "tal lembrança foi alimentada ao longo de O bandido" 
também ganhem uma outra conotação e, talvez, melhor se expliquem quando se tem ciência de sua existência.

A segunda narrativa começa com o anúncio "Decretado Estado de Sítio no País", nas primeiras seqüências do filme, com a "música de candomblé" de Terra em transe, que vai aos poucos subindo até se tornar intensa. Não muito tempo depois, vestígios desta segunda narrativa aparecem com o anão sendo preso e gritando: "O Terceiro Mundo vai explodir... quem tiver de sapato não sobra" É bom ressaltarque a imagem do anão sendo preso é apenas mais um caso de polícia, uma das mazelas a que tem de se dedicar o já cansado delegado Cabeção. É a voz over ${ }^{9}$ do anão que se refere a esta segunda narrativa.

Como imagem, a segunda narrativa surge pela primeira vez num rápido flash de policiais militares a cavalo. O caso de Mr. Schmidt, que teria provocado queda na Bolsa e fuga de capitais, a ela está relacionado, embora também esteja imbricado com as atividades de Luz, que, matando a mulher e a filha do empresário, teria detonado todo o processo que culmina com o suicídio de Mr. Schmidt (a versão do narrador painel eletrônico omite o episódio que envolve Jorge, lembrando apenas que o industrial, que já havia morado no país, suicida-se em Hamburgo).

A moldura do enunciado básico desta segunda narrativa é constituída pela música de Terra em transe; ela aparece logo na abertura do filme e se prolonga no final invadindo a apresentação dos créditos secundários, além de ter várias inserções no decorrer do filme. Seu significado de luta, transe e transformação é obvio para que assistiu ao filme de Glauber. Talvez para grifar essa intenção e facilitar a leitura do espectador, Sganzerla tenha sentido necessidade de reiterar de inúmeras maneiras o seu significado, e acaba acrescentando a ele um dado que nos parece de grande importância para esta segunda narrativa: a sensação de

9. Ao contrário da chamada voz off, que se refere ao que está sendo visto na tela, a voz over diz respeito a algo que se passa em outro espaço, em outro tempo, em outro assunto.

Significação 13 
absurdo, que é enfatizada pelas descontinuidades espaço-temporais, ausência de protagonistas e situações insólitas.

Constituida por vários enunciados emoldurados (figura da Compartimentagem, na linguagem dos retóricosdo Groupe |i, a segunda narrativa acentua-se no momento da chegada de JB ao país, vindo de uma viagem à Espanha e em campanha eleitoral para a Presidência - precisamente no momento em que seu avião aterrisa. Na cena em que Jorge, depois de revelar comportamentos estranhos num de seus assaltos, ao que tudo indica, tenta suicidar-se ingerindo tinta a óleo, na banda sonora ouvemse ruídos de animais selvagens, de metralhadoras, de explosões. Pouco depois da entrevista de JB no aeroporto, os locutores da rádio anunciam: "A situação do país parece ter se agravado..."A imbricação entre as duas narrativas intensifica-se.

No passeio à praia que Jorge faz com Janete Jane - o episódio mais rico do ponto de vista do entrelaçamento das duas narrativas - ele revela um lado político até então insuspeito ou, pelo menos, só perceptível retrospectivamente, quando se dá conta, por exemplo, do sentido ambíguo da reiterada frase "Quem tiver de sapato não sobra..." Na praia, Jorge, que ouve rádio e conversa descontraidamente com a namorada em seu carrão conversível, estranhamente responde a uma pergunta formulada pelo locutor, que pergunta: "Qual é o seu jogo?", e ele responde "Não faço jogo nenhum", como se se dirigisse à Janete Jane.

Pouco depois, há inserção de uma cena onírica, na qual Jorge aparece ao lado de presumíveis membros do bando Mão Negra (ou agentes da repressão?), a vozaparentementeoff: "Meu negócio era o poder. Quando a gente não pode fazer nada a gente avacalha." Grito evidentemente em over logo a seguir, como se ele estivesse sob tortura. Pouco depois, Jorge repete a mesma frase, mas está em outro lugar, na cena da tentativa de suicídio no mar, que também é onírica. Volta a dialogar com a namorada. Quando diz, quase gritando, "Mas isto vai acabar", desta vez é o locutor do rádio que responde: "Claro que vai acabar" 
Nova cena onírica, mas desta vez realizada com extremo realismo, como se se tratasse de tempo real da narrativa: Jorge aparece procurando por Jane, grita por ela e vai encontrá-la no alto de uma pedra da praia. Jorge ajuda a moça a descer, toma-a nos braços e beija-a apaixonadamente; há um corte imperceptível, seguido de fusão, e o beijo prossegue e termina com os namorados no banco do carro.

Na próxima cena, já é noite, e Jorge e Jane conversam deitados lado a lado na areia da praia. A conversa termina, sem corte perceptível, já no elevador de um prédio, presumivelmente do hotel em que mora Jorge. Ele, então, se abre com a namorada: fala sobre sua vida. Em off, depois de se referir à sua atividade internacional, revela: "Pra mim a solução era o terror, agora não é mais. A terceira guerra..." Conta que a mãe quis abortá-lo. E se desculpa: "Vai me desculpar se isso que estou dizendo é verdade ou simples mentira..." Recorda-se - agora em pormenores da tentativa de suicídio na praia. Vozes em over: "É a bomba. É a fome." Jorge ainda grita: "Separaram o Terceiro Mundo do resto da Terra!", como se estivesse sendo torturado.

Depois do passeio, Jorge descobre que Janete Jane o trai com outro homem, e ele entra em conflito com o bando Mão Negra e JB, a quem atribui o comando daquela organização. O modo como mata JB, colocando uma bomba no porta-malas do carro do político-bandido, é totalmente inverossímel se se considera o seu perfil de ladrão de mansões e tarado. Além disso, a cena preparatória do atentado vem com uma legenda: "Minha última bomba", insinuando outras que a precederam, evidentemente.

Fica claro então que as duas narrativas acontecem simultaneamente. E Jorge, neste momento que prepara o atentado à bomba, estaria mais para santo guerreiro do que nunca... Mas seu suicídio põe fim à primeira narrativa e a segunda, que prescinde dele, invade a película, soberana. A imagem de São Jorge se queima, a "música de candomblé" toma conta da banda sonora, caindo para background de vez em quando 
para permitir as últimas frases dos locutores da rádio. Os discos-voadores, atores não humanos de uma narrativa interpolada, relacionada com a segunda narrativa, aparecem agora por todos os lados, "vindos do Leste", segundo o locutor da rádio de Itapecerica, que ainda informa que "o céu está avermelhado" Favelados dançam em transe; no áudio a frase "Sozinho a gente não vale nada", e a voz feminina grita uma resposta: "E daí..."

O fogo aumenta na tela, destrói a figura de São Jorge.10 Corte. Enquadramento da lua no céu. A música de Terra em transe sobe. Só faltou aparecer na tela o fragmento do poema de Mário Faustino que Glauber cita no seu filme:

Não conseguiu firmar o nobre pacto

Entre o cosmos sangrento e a alma pura

Gladiador defunto mas intacto

(Tanta violência, mas tanta ternura)

Comparar o desclassificado Jorge com o poeta Paulo Martins, personagem de Terra em transe, pode ser lido como um sacrilégio, como uma atitude de humor negro de Sganzerla, ridicularizando a postura glauberiana, e com ela a do Cinema Novo. Afinal, não teria sido à toa, entre outras coisas que Sganzerla colocou o delegado Cabeção discursando contra a arte moderna e os intelectuais no episódio em que trata do roubo de uma mansão. Não pretendemos trazer para aqui esta polêmica, mas é inevitável levantara questão: é o bandido assaltante ou o político terrorista que está sendo identificado com o personagem Paulo Martins? Seja como for, não é para essa direção que nossa leitura aponta.

10. Bernardet (1991, p. 206) vê neste ato enunciativo uma evocação do Rosebud, de Orson Welles. 


\section{Quatro}

Se pudéssemos pensar a segunda narrativa como uma moldura da primeira, vislumbraríamos na relação entre elas a figura do Encolhimento, que ocorre quando o enunciado não ocupa inteiramente o espaço do quadro. Só que esse encolhimento agora é dinâmico e, em vez de termos um vazio envolvendo o enunciado, um outro enunciado, vindo do exterior, vai ocupando o seu lugar, até fazê-lo desaparecer, como os teóricos do Groupe ja, previam que pudesse acontecer numa situação limite, praticamente impossível de ocorrer nas artes plásticas. Nesse processo, a figura do Encolhimento ganha uma conotação hiperbólica e transforma-se na moldura Icônica ostensiva, na qual, pode-se dizer, o índice torna-se a mensagem.

Teríamos, assim, em O bandido uma espécie de alegoria in praesentia, na qual os dois discursos que a constituem, o comparante e o comparado, encontram-se manifestados no texto, pelo menos em parte. Isso obrigaria o leitor do texto fílmico a encontrar relações entre esses dois discursos imanentes à obra antes de relacioná-los com outros discursos transcendentes, mesmo quando implicados (pensamos numa precedência lógica, não fatual). Evidentemente, o discurso fílmico de $\mathrm{O}$ bandido não prescinde das relações intertextuais - as remissões a Glauber, Godard, Orson Welles e ao contexto político-ideológico em que ele se insere saltam aos olhos. A questão nos parece - e essa é a questão que queremos deixar no ar - é de como operar os mecanismos de intertextual idades para estabelecer essas "pontes" sem forçar o filme a dizer o que não disse ou, ao contrário, fazê-lo dizer apenas o já dito.

Significação $13 \cdot 160$ 


\section{Bibliografia}

Bernardet, Jean Claude. 1991 O vôo dos anjos. São Paulo: Brasiliense.

Greimas, A. J. 1973. Os atuantes, os atores, as figuras. In: Semiótica narrativa e textual. São Paulo: Cultrix/Editora da Universidade de São Paulo.

GROUPE p. 1970. Retórica geral. São Paulo: Cultrix/Editora da Universidade de São Paulo.

1989 Sémiotique et rhétorique du cadre. In: Dossier: topologie de l'énonciation, $\mathrm{n} .{ }^{\circ} 5$, Paris (cópia xerográfica).

1992. Traité du signe visuel - pour une rhétorique de I'image. Paris: Seuil.

Lacan, J. 1986. O seminário. Livro I - Os escritos técnicos de Freud. Rio de Janeiro: Jorge Zahar.

Ramos, Fernâo. 1987. Cinema marginal (1968/1973) - a representação em seu limite. São Paulo: Brasiliense.

Xavier, I. s/d. Alegoria, modernidade, nacionalismo (separata em cópia xerográfica).

1993. Alegorias do subdesenvolvimento - cinema novo, tropicalismo, cinema marginal. São Paulo: Brasiliense. 